\title{
DE EMPREGADO A EMPRESÁRIO: MUDANÇAS NO SENTIDO DO TRABALHO PARA EMPREENDEDORES
}

\author{
ONCE EMPLOYEE, NOW EMPLOYER: CHANGES ON THE MEANING OF WORK FOR \\ ENTREPRENEURS
}

\author{
Recebido em 24.10.2016. Aprovado em 04.12.2017 \\ Avaliado pelo sistema double blind review \\ DOI: http://dx.doi.org/10.12712/rpca.v11i5.836
}

\section{Ana Heloísa da Costa Lemos}

Pontifícia Universidade Católica do Rio de Janeiro (PUC-Rio), Rio de Janeiro/RJ, BRASIL aheloisa@iag.puc-rio.br

\section{Flavia de Souza Costa Neves Cavazotte}

Pontifícia Universidade Católica do Rio de Janeiro (PUC-Rio), Rio de Janeiro/RJ, BRASIL

flavia.cavazotte@iag.puc-rio.br

\section{Daniel Oswaldo Santana de Souza}

Pontifícia Universidade Católica do Rio de Janeiro (PUC-Rio), Rio de Janeiro/RJ, BRASIL dossouza@gmail.com

\section{Resumo}

Este artigo tem como objetivo analisar as mudanças no sentido do trabalho para indivíduos que deixaram de ser empregados para serem empreendedores. A partir de entrevistas realizadas com 15 empreendedores, quatro dimensões principais de mudança foram identificadas. A carga de trabalho intensifica-se, porém, é acompanhada por recompensas financeiras superiores. $O$ trabalho, antes visto como promotor de segurança, torna-se uma fonte de autodeterminação e de qualidade de vida. O senso de responsabilidade por resultados aumenta, devido à necessidade de uma atitude mais responsiva associada à condição de empresário. E o reconhecimento profissional, originalmente pautado pelos pares e superiores, abre espaço para a expansão na autoestima, através da percepção de eficácia pessoal, baseada nos resultados do próprio negócio. Com estes achados, a pesquisa contribui para expansão do conhecimento acerca do fenômeno do sentido do trabalho, uma vez que retrata o dinamismo da construção deste sentido, ao longo da trajetória profissional do indivíduo, perspectiva pouco usual nos estudos sobre o tema.

Palavras-chave: Sentido do trabalho. Empreendedor. Mudança de Carreira.

\begin{abstract}
This article aims to analyze the changes in the meaning of work for individuals who once were employees, but now are entrepreneurs. Data collected from interviews with 15 entrepreneurs led to four main vectors of change. The workload intensifies, however, it goes along with higher financial rewards. The work, once seen as a source of security, provided by the employee status, becomes a source of self-determination and quality of life, as an entrepreneur. The sense of responsibility concerning the results of the work increases due to the need of a more responsive attitude, related to the entrepreneur condition. And professional recognition, originally suggested by peers and superiors, makes room for an expansion in self-esteem, through the perception of personal effectiveness, based on their own businesses results. This research contributes to the expansion of knowledge on the meaning of work phenomenon, once it registers the dynamism of the concept throughout individual's professional pathway, an unsual approach about the subject.
\end{abstract}

Keywords: Meaning of work. Entrepreneur. Career Change. 


\section{Introdução}

Para um número considerável de indivíduos, o trabalho tem um papel central na construção da identidade, no senso de competência e de valor social. A importância do trabalho na contemporaneidade tem motivado a realização de pesquisas sobre os significados subjetivos que as pessoas atribuem à essa atividade, bem como sobre os impactos das experiências vivenciadas no seu contexto (Rosso, Dekas e Wrzesniewski, 2010). Tipicamente, a literatura sobre o sentido do trabalho tem se concentrado em explorar os mecanismos de significação em si, investigando os diferentes sentidos atribuídos ao trabalho pelos indivíduos, enfocandoos como relativamente estáveis para cada pessoa. No entanto, mudanças na vida profissional, sejam elas de status, de papel ao longo da carreira ou de empregador podem provocar alterações no sentido do trabalho, para um mesmo sujeito (Ashforth, 2001).

Apesar de as organizações serem o ambiente no qual os indivíduos iniciam, tradicionalmente, sua inserção no mundo do trabalho, empregando-se em seus quadros, constata-se que há um movimento alternativo à inserção na "grande empresa", que se manifesta no volume significativo de criação de novos empreendimentos (Vale, 2014). O Brasil se destaca neste cenário, pois, de acordo com o Global Entrepreneurship Monitor, o país alcançou o melhor desempenho no ranking de empreendedorismo por oportunidade entre os Brics (Sebrae, 2015). Essa "vocação empreendedora" nacional tem se mostrado bastante atraente, sobretudo para os jovens: pesquisas apontam que $78 \%$ deles pretendem estar à frente de seu próprio negócio em um horizonte de 10 anos (EAESP, 2014). Porém, o desejo de empreender não aparece apenas nas aspirações daqueles que ainda não ingressaram no mercado de trabalho. Um contingente significativo de trabalhadores que iniciaram suas carreiras em empresas privadas vem optando por trocar a condição de empregado pela de empregador (Sebrae, 2015). Essa constatação, aliada à carência de estudos voltados para entender transições profissionais, motivou a realização do presente trabalho, que analisa as mudanças no sentido do trabalho para indivíduos que deixaram de ser empregados para serem empreendedores. Acreditase que deixar de ser empregado para ser empresário envolve tanto mudanças concretas nas atividades profissionais, quanto mudanças na experiência subjetiva do trabalho. Buscou-se, dessa forma, entender quais seriam essas mudanças.
Para alcançar o objetivo proposto, estruturou-se o artigo em cinco tópicos, incluindo esta introdução. O segundo tópico foi dedicado a apresentar aspectos referentes ao movimento empreendedor no Brasil, bem como a discutir a literatura sobre sentido do trabalho. No terceiro são abordados os aspectos metodológicos da pesquisa. No quarto tópico são analisados os resultados e, no último, são apresentadas as considerações finais.

\section{Referencial Teórico}

\section{Empreendedorismo no Brasil: um breve panorama}

Baron (2002) afirma que por empreendedorismo temse um complexo processo através do qual indivíduos reconhecem oportunidades e se mobilizam em ações com o objetivo de obter benefícios econômicos consideráveis. Um dos autores de maior destaque no assunto, o economista austríaco Schumpeter (1982), evidenciou a relação da atividade empreendedora com a inovação e cunhou o termo "destruição criativa" referente às novidades resultantes das ações tomadas frente às oportunidades identificadas. De acordo com o autor, o status quo seria destruído em benefício da profusão criativa.

Favoreto, Binder e Campos (2012), visando sistematizar teoricamente o conceito, argumentam que o foco no indivíduo é apenas uma das diferentes óticas sob as quais o empreendedorismo pode ser observado existiriam ainda, além da "visão do empreendedor", a "visão do empreendimento" e a "visão do processo empreendedor". Para esta pesquisa, torna-se mais relevante o aprofundamento conceitual baseado no primeiro ponto de vista.

Vale (2014) caracteriza o empreendedor como um ator particular, multidimensional e complexo. Este seria também dotado de uma visão oportunista e utilitarista do mundo (visão derivada da economia), motivado por impulsos interiores (ciência do comportamento), interesses simbólicos e sociais (ciências sociais e sociologia econômica) e capaz de proporcionar, nos lugares em que desenvolve seus empreendimentos, mudança, progresso e crescimento econômico.

De acordo com Favoreto et al. (2012), os primeiros estudos relacionados ao construto empreendedorismo direcionavam a atenção às características e fatores individuais em destaque na figura do empreendedor. A linha dos "comportamentalistas", apontada 
por Fillion (1999), procurava a explicação do comportamento empreendedor no comportamento humano. Nessa linha, merecem atenção as pesquisas de McClelland (1961), acerca das necessidades do empreendedor. Foram identificados pelo autor três fatores motivacionais que lançavam o indivíduo à atividade empreendedora, são elas: realização referente à superação de limites; afiliação - sobre a entrada e permanência num determinado grupo social de interesse; e poder - quanto à capacidade de influência sobre terceiros.

Busenitz et al. (2003) afirmam que o nicho acadêmico dedicado ao estudo do empreendedorismo, apesar de ter atraído a atenção de muitos pesquisadores, teria se expandido de maneira multidisciplinar e, por isso, ainda tem uma limitada estrutura científica. Pode-se dizer que, como construto, o "empreendedorismo" ainda estaria numa fase de "construção teórica" (Wiseman e Skilton, 1999).

No caso do Brasil, a avaliação da dinâmica empreendedora propriamente dita vem sendo monitorada por meio de pesquisas sistemáticas. Alguns dados numéricos referentes à atividade empreendedora no país são atualizados anualmente pelo Serviço Brasileiro de Apoio às Micro e Pequenas Empresas (Sebrae), através do levantamento realizado para o Global Entrepreneurship Monitor - um projeto internacional, cujo objetivo é o de analisar o impacto do empreendedorismo no desenvolvimento econômico dos países (Sebrae, 2015).

De acordo com a supracitada pesquisa, em 2014, a taxa total de empreendedores no Brasil, como percentual da população entre 18 e 64 anos, foi de $34 \%$ - cerca de 46 milhões de indivíduos. O registro mantém-se em trajetória crescente desde 2011 e, em comparação com 2013, marca um acréscimo de 2,2 pontos percentuais. A motivação por trás da entrada no mercado empreendedor também é investigada no levantamento. De acordo com os dados mais recentes, $70,6 \%$ dos empreendedores optam por tocar seus próprios negócios, mesmo tendo acessíveis alternativas de emprego - o chamado empreendedorismo por oportunidade (Sebrae, 2015).

Em um dos itens do relatório são tratadas as percepções da população brasileira em relação ao empreendedorismo, a fim de estimar o grau de disposição e o potencial referentes ao tema. Apesar da crise, em 2014, 55,5\% da população declarou-se otimista quanto à percepção de boas oportunidades para iniciar um negócio nos próximos seis meses. Metade dos consultados acredita possuir os conhecimentos, habilidades e experiências necessárias para a atividade empreendedora e quase 61\% não tem o medo do fracasso como um fator impeditivo para o envolvimento na criação de um novo negócio. O desejo de empreender (31,4\%) só fica atrás do desejo da casa própria $(41,9 \%)$ e do de viajar pelo Brasil (32\%) de acordo com um ranking de sonhos e expectativas aferido para a população adulta brasileira. A título de comparação, o desejo de fazer carreira em alguma empresa ocupa a sétima posição - 15,8\% - da lista, sugerindo uma preferência dos brasileiros por ter o próprio negócio, em detrimento da carreira tradicional (Sebrae, 2015).

Uma vez compreendido o contexto que envolve a opção pela carreira empreendedora, cabe questionar o sentido atribuído pelos novos empresários à tal atividade. Que sentido tinha o trabalho como empregado? O que mudou após a decisão por abrir um negócio? A fim de endereçar tais questões, o tópico a seguir contempla a discussão referente ao sentido do trabalho, delimitando as origens e os processos referentes à dotação de sentido à atividade profissional.

\section{O Sentido do Trabalho}

Os termos sentido e significado do trabalho têm sido alvo de discussão no meio acadêmico (Tolfo et al. 2005): ora o termo "sentido" é utilizado para se referir a experiência subjetiva do indivíduo no trabalho, ora é o termo "significado" que é mobilizado. Todavia, Tolfo e Piccinini (2007) firmam-se na estrutura etimológica dessas palavras e argumentam em favor do uso delas tais como sinônimos, sendo esta a abordagem adotada neste artigo. No entanto, apesar da escolha por essa abordagem conceitual, cabe destacar que existe um considerável corpo de pesquisa que questiona essa suposta obviedade na definição do termo (Brief e Nord, 1990; MOW International Research Team, 1987; Super e Sverko, 1995, Cavalheiro, 2010; Tolfo et al. 2011). Pretende-se aqui apresentar um panorama da produção acadêmica relacionada ao tema, às origens e aos processos pelos quais o indivíduo atribui sentido à sua atividade profissional.

As pesquisas do campo de comportamento organizacional nutrem-se majoritariamente de duas fontes, na intenção de estudar o construto: psicologia e sociologia. De acordo com a primeira linha de pesquisa - mais relevante para esse trabalho, uma vez que serão analisadas percepções individuais do sentido 
do trabalho - as bases da construção do significado do trabalho partiriam de subjetividades individuais resultantes da vivência profissional (Baumeister, 1991; Brief e Nord, 1990; Wrzesniewski, 2003).

Os anos 1950 são apontados como o marco inicial dos estudos que tentam compreender os mecanismos de significação do trabalho pelo indivíduo (Morin, Tonelli e Pliopas, 2007). Todavia, o trabalho realizado pelo Meaning of Work International Research Team, em 1987 (MOW, 1987) é tido como uma referência na pesquisa sobre o tema: trata-se do primeiro modelo teórico do conceito, relacionando valores, crenças e expectativas que os empregados teriam em relação ao trabalho (Perezgonzáles e Vilela, 2005).

No modelo final proposto pela equipe de pesquisadores, o sentido do trabalho é composto por três dimensões, que são: a) centralidade do trabalho; b) normas sociais e c) objetivos e resultados valorizados do trabalho. A primeira refere-se à quão importante ou central, o trabalho é para o indivíduo. A segunda versa sobre as convenções sociais que circundam a experiência profissional (direitos versus deveres, pressões sociais relacionadas à vida profissional que influenciam o comportamento humano, como tecnologia, diversidade e globalização, por exemplo). A última dimensão trata dos resultados advindos da atividade profissional e dos objetivos que a impulsionam, como fonte de renda, de contatos interpessoais e status, por exemplo (Kubo e Gouvêa, 2011).

Desde então, muitos pesquisadores se debruçaram sobre o tema. Dessa variedade científica produzida ao longo de quase três décadas, argumenta-se que o construto sentido do trabalho ainda carece de estruturas generalistas, que possibilitem sua maior integração, consistência e compreensão (Rosso, Dekas e Wrzesniewski, 2010). No sentido de estabelecer certa unidade a esse corpo teórico, Rosso, Dekas e Wrzesniewski (2010) elaboraram uma revisão do estado-da-arte do construto. Com base nesse trabalho, pretende-se apresentar um panorama da pesquisa acadêmica que descreve as origens e os mecanismos de significação da atividade profissional.

\section{Origens do Sentido do Trabalho}

Quanto às origens do significado do trabalho para o indivíduo, o trabalho de Rosso, Dekas e Wrzesniewski (2010) identificou quatro fontes principais: "self", "outros", "contexto" e "espiritualidade". O conceito de "self" faz referência ao "eu" do indivíduo como principal vetor de comportamentos, atitudes e crenças que influenciariam a maneira pela qual o indivíduo atribui significado ao seu trabalho. Tal construto seria maleável e sofreria influência direta das percepções, das experiências e do contexto de trabalho (Ashforth e Mael, 1989). Rosso, Dekas e Wrzesniewski (2010) destacam, na revisão teórica, três dimensões comumente estudadas desta fonte: valores, motivações e crenças relacionadas ao trabalho. A primeira seria resultado de pressões sociais, interpessoais e experiências profissionais e trataria do modo final ao qual o trabalhador aspira e se vê capaz de realizar através da sua atividade profissional. Já "motivação" trataria da medida com a qual o indivíduo desempenha seu trabalho, vivenciando positiva e eficientemente tal dinâmica. Finalmente, as "crenças" se desdobrariam em três itens: a) envolvimento e centralidade profissionais - quanto à significância do trabalho na vida do indivíduo; b) orientação profissional - quanto ao modo pelo qual o indivíduo compreende o que o seu trabalho significa, como pretende trabalhar e o porquê do trabalho e c) chamados - quanto a predisposições individuais que seriam pessoalmente e socialmente significativas.

Sobre os "outros" como fonte de significado do trabalho, a revisão teórica aponta para relação de líderes, grupos e comunidades e da família, como interfaces de influência na dotação de sentido à experiência profissional para o indivíduo.

Em referência ao "contexto", os pesquisadores salientam cinco dimensões desta fonte de significado do trabalho. São elas: a) desenho do trabalho - quais são as tarefas correspondentes ao indivíduo sob determinado cargo; b) missão organizacional - a afirmação dos objetivos e valores básicos de uma organização; c) circunstâncias financeiras - sobre a situação econômica do indivíduo, se pobre, rico, remediado, etc; d) domínios não-profissionais relacionados aquilo que está além do ambiente de trabalho; e finalmente e) cultura nacional - fatores que podem variar de acordo com a nacionalidade.

A última fonte de significado do trabalho, a "espiritualidade", seria uma referência à uma "força superior", um "credo" (Hill e Pargament, 2003). Rosso, Dekas e Wrzesniewski (2010) afirmam que ainda é tímida a produção científica que aponta para a espiritualidade como uma fonte de significado de trabalho. Em vez disso, pesquisas nessa linha relacionam a atividade profissional a um tipo de vocação. 


\section{Mecanismos de Significação do Trabalho}

Quanto aos mecanismos pelos quais o trabalho ganha significado são identificados sete principais processos. Por "mecanismos" entendam-se o "por quê" e o "como" a atividade profissional passa a ser dotada de significado para o indivíduo (Stinchcombe, 1991), que podem variar de fatores intrapsíquicos, objetivando a satisfação do eu, até aqueles totalmente externos ao trabalhador. Eles foram listados como: "autenticidade", “autoeficácia”, “autoestima", "propósito", "pertencimento", "transcendência”, "significação cultural e interpessoal" (Rosso, Dekas e Wrzesniewski, 2010).

Por "autenticidade", tem-se o alinhamento entre o comportamento individual e as percepções do seu "verdadeiro" eu. (Markus, 1977; Ryan, Deci e Grolnick, 1995; Sheldon et al., 1997 apud Rosso, Dekas e Wrzesniewski, 2010). De acordo com os pesquisadores, tal mecanismo pode se manifestar de três formas: a) auto concordância - quando o indivíduo acredita que age conforme seus valores $\mathrm{e}$ interesses; b) afirmação - referente à identificação, ativação e afirmação de identidades de importância para o sujeito no ambiente de trabalho; c) engajamento pessoal - quando o trabalhador se vê verdadeiramente submerso, engajado na sua ocupação.

O mecanismo da "auto eficácia" trata da certeza do indivíduo de sua capacidade de agir de forma efetiva no seu trabalho, a fim de cumprir com um determinado objetivo. Também desdobra-se em três tipos de manifestação: a) autonomia - tem a ver com sensação de poder fazer algo; b) competência - relacionada aos sucessos frente aos desafios constantes do ambiente profissional e c) impacto percebido - quando o trabalhador é capaz de perceber os efeitos do seu trabalho. Sobre "autoestima", entende-se como a capacidade de autovalorização.

Quanto ao mecanismo "propósito" - referente à ideia de intencionalidade das ações - ele se desdobra em dois tipos de manifestações: a) significância do trabalho - a quão "importante" determinada atividade seja e b) sistema de valores - um tipo de determinação social do que seja certo ou errado.

Sobre o mecanismo "pertencimento" - quando o indivíduo se vê motivado a manter-se relacionado a outros indivíduos ou grupos - também são identificados dois tipos de manifestação: a) identificação social - relacionamentos com grupos e b) conectividade interpessoal - relacionamento com outros indivíduos no ambiente de trabalho.

Em "transcendência" - a conexão com algo "superior", "maior que o eu" - Rosso, Dekas e Wrzesniewski (2010) identificam duas formas de atribuição de significado ao trabalho: a) interconexão - tem a ver com a ideia de estar contribuindo com algo maior do que aspirações egocêntricas e b) abnegação - relacionado a sujeição de si próprio a algo externo.

Já o processo de "significação cultural e interpessoal", a equipe de pesquisadores aferiu que tanto via interações indivíduo - coletividade, ou indivíduo indivíduo, podem agir como mecanismos de dotação de sentido à atividade profissional.

\section{Aspectos metodológicos}

A fim de entender as mudanças no sentido do trabalho para indivíduos que fizeram a transição de carreira da condição de empregado para a de empresário, optou-se por uma pesquisa de natureza qualitativa, baseada em entrevistas em profundidade, realizadas com egressos de empresas privadas que criaram seus próprios empreendimentos. Assim, garantiu-se que todos os participantes tivessem partido de uma experiência profissional como assalariado, prévia ao empreendimento, para caracterizar a transição no status profissional.

Tendo em vista os objetivos da pesquisa, definiu-se que o perfil desejado de entrevistados deveria atender, sobretudo, à condição deste ser um(a) empresário(a) com vivência anterior como empregado(a) de alguma empresa privada. Não julgamos relevante criar limites relativos à idade, escolaridade, gênero, nem mesmo experiência de trabalho na iniciativa privada, por entendermos que a diversidade de perfis, neste caso, traria maior riqueza ao entendimento do caráter dinâmico da construção do sentido do trabalho. Neste sentido, a seleção dos entrevistados obedeceu ao critério da acessibilidade, tendo sido identificados os sujeitos de pesquisa por meio da rede de contatos dos pesquisadores. Foram entrevistados 15 empreendedores do Estado do Rio de Janeiro, com idade média de 37 anos, com escolaridade e ramo de atuação variados. A média de idade dos empreendimentos é de sete anos - num intervalo que vai de um a 22 anos - e seus ramos de atuação compreendem serviços, produção audiovisual e varejo. 
A procura por novos sujeitos de entrevista cessou quando julgamos ter atingido a saturação, isto é, quando percebemos que não havia mais temas novos nos relatos dos entrevistados. A repetição dos temas começou a aparecer por volta da décima entrevista, todavia julgamos pertinente entrevistar mais alguns empresários, para nos asseguramos da percepção de saturação. (Tabela 1)

Tabela 1. Perfil dos entrevistados

\begin{tabular}{|c|c|c|c|c|c|c|}
\hline Identificação & Gênero & Idade & $\begin{array}{l}\text { Grau de } \\
\text { instrução }\end{array}$ & $\begin{array}{l}\text { Função } \\
\text { anterior }\end{array}$ & $\begin{array}{l}\text { Ramo do novo } \\
\text { negócio }\end{array}$ & $\begin{array}{c}\text { Idade da } \\
\text { empresa } \\
\text { (anos) }\end{array}$ \\
\hline E1 & $\mathrm{F}$ & 28 & Pós-graduação & $\begin{array}{l}\text { Edição de } \\
\text { imagens }\end{array}$ & $\begin{array}{l}\text { Produção } \\
\text { audiovisual }\end{array}$ & 5 \\
\hline E2 & M & 30 & Pós-graduação & $\begin{array}{l}\text { Edição de } \\
\text { imagens }\end{array}$ & Varejo eletrônico & 2 \\
\hline E3 & M & 29 & Pós-graduação & $\begin{array}{l}\text { Analista de } \\
\text { marketing }\end{array}$ & $\begin{array}{l}\text { Produção } \\
\text { audiovisual }\end{array}$ & 6 \\
\hline E4 & $\mathrm{F}$ & 26 & $\begin{array}{l}\text { Ensino } \\
\text { superior }\end{array}$ & $\begin{array}{l}\text { Analista de } \\
\text { negócios }\end{array}$ & Varejo eletrônico & 1 \\
\hline E5 & $\mathrm{F}$ & 27 & $\begin{array}{l}\text { Ensino } \\
\text { superior }\end{array}$ & $\begin{array}{l}\text { Analista de } \\
\text { marketing }\end{array}$ & $\begin{array}{l}\text { Produção } \\
\text { audiovisual }\end{array}$ & 5 \\
\hline E6 & $\mathrm{F}$ & 28 & Ensino médio & $\begin{array}{l}\text { Gestão de } \\
\text { eventos }\end{array}$ & Eventos e varejo & 6 \\
\hline E7 & M & 27 & Ensino médio & $\begin{array}{l}\text { Gestão de } \\
\text { eventos }\end{array}$ & Eventos e varejo & 6 \\
\hline E8 & $\mathrm{F}$ & 32 & Pós-graduação & $\begin{array}{l}\text { Gestão } \\
\text { financeira }\end{array}$ & Varejo & 3 \\
\hline E9 & $\mathrm{F}$ & 29 & Ensino médio & Designer & Varejo & 3 \\
\hline E10 & M & 56 & $\begin{array}{l}\text { Ensino } \\
\text { fundamental }\end{array}$ & $\begin{array}{l}\text { Vendas no } \\
\text { varejo }\end{array}$ & Varejo & 8 \\
\hline E11 & $\mathrm{F}$ & 62 & Pós-graduação & Direção RH & Consultoria & 22 \\
\hline E12 & M & 65 & Pós-graduação & $\begin{array}{l}\text { Consultoria } \\
\mathrm{RH}\end{array}$ & Consultoria & 22 \\
\hline E13 & $\mathrm{F}$ & 42 & Ensino médio & $\begin{array}{l}\text { Gestão de } \\
\text { varejo }\end{array}$ & Ensino & 2 \\
\hline E14 & $\mathrm{F}$ & 28 & $\begin{array}{l}\text { Ensino } \\
\text { superior }\end{array}$ & $\begin{array}{l}\text { Web } \\
\text { designer }\end{array}$ & $\begin{array}{l}\text { Estúdio } \\
\text { fotográfico }\end{array}$ & 4 \\
\hline E15 & $\mathrm{F}$ & 53 & Ensino médio & Secretaria & Moda (indústria) & 13 \\
\hline
\end{tabular}

Fonte: Elaborada pelos autores.

As entrevistas duraram, em média, trinta minutos e foram baseadas em um roteiro elaborado pelos pesquisadores, com perguntas que versavam sobre a história dos empreendimentos, os significados da atividade profissional em momentos distintos, tangenciando questões referentes às origens e aos mecanismos de dotação de sentido do trabalho - tanto como empregados, quanto como empreendedores. Todas as entrevistas foram gravadas com o consentimento dos participantes de forma a possibilitar a posterior transcrição. O método empregado para a análise dos relatos coletados foi a análise de conteúdo, numa abordagem abdutiva - referente à combinação sistemática entre os dados do campo e o referencial teórico (Dubois e Gadde, 2002). 
Ao analisarem as transcrições, os pesquisadores buscaram identificar os principais aspectos que delineavam o sentido do trabalho para os entrevistados em seus dois momentos profissionais: na antiga condição de empregado e, na atual, de empresário. Buscou-se, assim, delinear o caráter dinâmico dessas construções de sentidos, associando-as às transições vivenciadas pelos respondentes. Tais aspectos são expressos nas categorias criadas pelos pesquisadores para estruturar a análise e discussão dos dados. Estas categorias foram baseadas na discussão teórica acerca do sentido do trabalho, apesar de incluírem, também, temas que não aparecem, corriqueiramente, na referida literatura. Como a intenção deste trabalho era de não somente mapear os sentidos atribuídos ao trabalho pelos entrevistados, mas também destacar o dinamismo dessa construção, a análise foi estruturada com base nos sentidos captados e na mudança dessa atribuição de sentido, identificada nos relatos. O item seguinte apresenta e discute esses achados.

\section{Apresentação e Discussão dos Resultados}

Conforme anteriormente destacado, ao se analisar os relatos dos entrevistados buscou-se identificar os principais sentidos associados ao trabalho que perpassam as mudanças por estes vivenciadas. Dado que os entrevistados optaram por trocar a condição de empregado pela de empregador, estes tinham não só motivações para abraçar a nova escolha, mas também razões para deixar a condição anterior. Buscou-se explorar, especificamente, os diferentes sentidos do trabalho subjacentes a essas duas situações profissionais. Dessa forma, a análise enfatiza a substituição dos sentidos relativos à experiência de trabalho anterior, por novos sentidos associados ao exercício da atividade empresarial. Estes aspectos são discutidos a partir de quatro eixos, a seguir apresentados.

\section{Trocando menos horas de trabalho por uma carga mais intensa, mas com maiores ganhos}

A menção ao aumento da dedicação e da carga de trabalho foi uma constante nas declarações dos entrevistados. Quase todos relataram que trabalham muito mais horas hoje do que quando eram empregados. Tal intensificação sugere que o trabalho segue sendo central na vida desses sujeitos (MOW, 1987), quiçá ainda mais importante do que era quando estavam na condição de empregados. Todavia, apesar do aumento da sobrecarga de trabalho, os entrevistados parecem não se importar muito com esse fato, pois valorizam o principal retorno que este maior envolvimento lhes trouxe: maior ganho financeiro. As falas seguintes ilustram esse ponto:

"Trabalho quase 12 horas por dia,
incluindo finais de semana, mas lucro em
um mês aproximadamente o que ganhava
por ano na iniciativa privada, então acho
que vale a pena." (E8)
"Antigamente, eu emendava os feriados,
saia cedo... Agora é ralação! As vezes
tenho que ficar até mais tarde, quando
temos que decidir alguma coisa, tenho que
ir à comunidades perigosas onde temos
lojas, como o Alemão e a Rocinha... Isso
é bem difícil para mim. As vezes penso
em desistir... Mas o retorno (financeiro) é
muito bom.” (E6)
"Você vê tudo por outro ângulo. Em 17
anos, só tirei férias três vezes, ainda assim,
tenho que deixar o celular ligado. Em
compensação, financeiramente, eu tenho a
vida que sempre sonhei! Não falta nada
para a minha familia e ainda emprego
para mais de 80 pessoas.” (E10)

Mas não é somente porque ganham mais que os entrevistados aceitam trabalhar mais. $O$ fato de considerarem que este esforço se reverte também em maior satisfação, por se fazer o que se gosta, ou por ver-se como dono do seu próprio destino:

"Sem dúvida nenhuma eu trabalho
muito mais agora. Trabalho muito, mas
é diferente quando você trabalha pra você,
não se sente explorado, porque a decisão é
sua." (E10)

"Eu trabalho mais agora. Antes, tinha os finais de semana... Agora, normalmente passo os finais de semana trabalhando e durante a semana tenho que responder emails, visitar clientes e tratar as fotos minhas e as do meu marido, que tem um emprego regular durante a semana. Mas acho que sou mais feliz agora, ganho mais e gosto do que eu faço." (E14)

"Aumentou (o trabalho), sobretudo no 


\begin{abstract}
início, que éramos só nós dois e tínhamos que provar para os grandes clientes que decidiram seguir minha sócia, que só nós dois e uma secretária éramos tão eficazes quanto a nossa antiga empregadora, com toda a infraestrutura. É muito trabalho, mas é diferente quando o negócio é seu, não sei explicar... Acho que é o fato de estar trabalhando pra você, "defendendo o seu nome." (E12)
\end{abstract}

Tais declarações evidenciam uma movimentação quanto à origem do sentido do trabalho, de fatores contextuais, para fatores totalmente voltados ao "eu", levando em consideração a terminologia definida por Rosso, Dekas e Wrzesniewski (2010). Percebe-se uma valorização positiva da contrapartida do aumento na intensidade do trabalho - seja pelo retorno financeiro, pelo prazer em fazer algo que se deseja ou pela sensação de estar se esforçando em prol daquilo que é "seu". Tais declarações indicam que, dentre os entrevistados, auto-eficácia, autoestima e propósito tomam espaço como mecanismos mentais de dotação de sentido à atividade profissional empreendedora (Rosso, Dekas e Wrzesniewski, 2010), além de chamarem a atenção para uma mudança referente aos resultados esperados do trabalho (MOW, 1987). Tais fatos podem ser evidenciados pelo destaque que os entrevistados dão à própria capacidade de atuar efetivamente em suas novas funções, pela valorização que dão aos próprios esforços e à ciência que tinham dos objetivos que pretendiam alcançar com suas escolhas profissionais.

\section{Trocando a segurança de ser empregado pelos riscos como empreendedor e maior autodeterminação}

Além do aumento da carga de trabalho, em seus relatos alguns entrevistados mencionaram que a troca da condição de empregado pela de empregador significou a renúncia à uma condição de relativa segurança e estabilidade, em busca de uma situação profissional que, apesar de mais incerta, propiciava-lhes um sentimento de autodeterminação. Ao mencionar o trabalho anterior, a Entrevistada 1 reconhece que sua opção por este trabalho era decorrente da estabilidade que este propiciava, fundamental em um determinado momento de sua vida:

$$
\begin{aligned}
& \text { "Olha, na verdade en busquei esse } \\
& \text { trabalho na X por uma questão de }
\end{aligned}
$$

estabilidade mesmo. Foi exatamente quando eu decidi sair de casa e alugar um apartamento... E como 'freela', apesar de eu ganhar muito mais, tipo, a média era o dobro... Acabava que tinha mês que era o dobro, mas tinha mês que era nada. Quer dizer, nunca foi nada... Mas eu buscava estabilidade e tranquilidade mesmo." (E1)

Todavia, apesar da segurança conquistada como empregada, o desejo de fazer o que gostava, de determinar os rumos do próprio trabalho, motivaramna a abrir uma empresa:

"Me motivou a abrir a empresa foi (o
fato de) poder trabalhar com coisas que eu
gostava (...) E en já estava fazendo muito
'freela', estava fazendo mais dinheiro
do que na estabilidade da produtora e
enfim(...) Foi um processo que já acontecia
há muito tempo, porque como eu quis
abrir a empresa - eu acho que eu estava
na faculdade ainda, quando eu pensei em
abrir a empresa, o CNPJ." (E1)

Neste ponto também se percebe a mudança da fonte de significado de trabalho de fatores externos ao indivíduo - os outros - para determinantes egocêntricos - o self (Rosso, Dekas e Wrzesniewski, 2010). A renúncia a uma opção mais segura, todavia menos autônoma, está subjacente à fala do entrevistado que, tendo empresas consolidadas na família, optou por criar o próprio negócio:

\begin{abstract}
"Meu pai tem várias empresas. Eu sempre tive esse exemplo em casa e tinha a vontade de ter o men negócio... Eu nunca quis cuidar das empresas dele. Eu poderia trabalhar numa das empresas dele e ganhar bem mais. Mas eu gosto de ter a minha empresa, tomar as minhas decisões.” (E3)
\end{abstract}

Os depoimentos ressaltam, também, uma mudança atinente às normas sociais relacionadas ao trabalho (MOW, 1987), pois a segurança representada pela empresa empregadora, tal como uma instituição que "absorveria" todas as pressões contextuais, cede 
espaço para uma certa vulnerabilidade do sujeito empreendedor, que assumiria esse impacto em prol de uma maior autodeterminação. O desejo de determinar o próprio destino aparece também na fala da entrevistada que ressalta o fato de que, por ter sua empresa, pode gerenciar seu tempo e conciliar as demandas profissionais com as familiares:

"Men trabalho agora significa qualidade de vida, qualidade de tempo com a minha filha, com a minha familia e me dá prazer! É uma coisa que en tenho aprendido muito e tenho planos de crescimento com ela (a empresa). Conforme a minha filha vá crescendo, eu também espero que a minha empresa vá crescer." (E4)

Destas declarações percebe-se a ação dos três processos citados anteriormente - auto-eficácia, autoestima e propósito. Além deles, um quarto mecanismo - o da autenticidade (Rosso, Dekas e Wrzesniewski, 2010) - pode ser destacado, uma vez que à frente de seus negócios, os empreendedores percebem-se alinhados aos seus objetivos de vida e àquilo que se consideram aptos de realizar profissionalmente, vendo-se capazes e realizados em suas ações.

\section{Trocando menos obrigações por mais responsabilidades, com um senso de propósito}

A mudança profissional vivenciada pelos entrevistados implicou não apenas em assumir maiores riscos, mas também em aumentar as responsabilidades. Se, na condição de empregados, estes tinham menos responsabilidades, agora como empregadores as responsabilidades ampliaram-se significativamente:

"Ah, ser funcionário é infinitamente mais fácil. Mas só o negócio próprio pode me dar o que en busco. Busco alto retorno financeiro no meu trabalbo. Tem que valer a pena! Tem que mudar a minha vida." (E7)

"Aumentou muito. Quando comecei, tinha pouca infraestrutura e quase a mesma quantidade de trabalho. Tive que me desdobrar. Mas com todos os problemas, quando você passa de empregado para empregador, você se sente evoluindo e ai isso te estimula a querer crescer mais e mais.” (E13)
"É outro tipo de dinâmica, na verdade, hoje em dia eu tenho uma responsabilidade muito maior. Tenho que dar exemplo para as pessoas que trabalham comigo, tem que fazer um pouco... Ele (o trabalho) representa uma responsabilidade que é super prazerosa...” (E1)

A certeza de sua capacidade de agir com sucesso em sua atividade profissional - autoeficácia (Rosso, Dekas e Wrzesniewski, 2010) - é notória nas declarações destes empresários. Mas os entrevistados não assumiram mais responsabilidades e abriram mão do "conforto" de ter um chefe responsável pelas principais decisões, por acaso. Ao abraçarem suas novas responsabilidades, estavam trocando uma condição aparentemente mais confortável, pela possibilidade de realizar algo que lhes conferia um senso de propósito e autorrealização:

"Cara, às vezes acho que vou ficar maluca, é muito trabalho. Mesmo assim en diria que é muito mais fácil ser funcionário do que dono do próprio negócio, trabalho mais e é mais estressante porque a responsabilidade é muito grande, o cliente é seu chefe, mas a grande vantagem é que o resultado do sen trabalho vai todo pra você.” (E6)

"Agora é dificil, en praticamente não tenho vida social, porque sou eu quem tem que decidir tudo. Já cheguei a trabalhar 17 horas seguidas, mas eu faço isso porque eu tenho um objetivo, que é ter uma vida tranquila. Me esforço agora, pra mais tarde poder fazer o que quiser." (E7)

"É mais fácil ser funcionária. Qualquer problema você chama o seu superior. Mas ser dona do próprio negócio também tem vantagens. Tenho o meu próprio negócio para ganbar dinheiro, mas também quero ter liberdade para tomar minhas decisões. Corro riscos, mas os retornos são só meus também. Tudo muda. O contexto é totalmente diferente. Antes recebia ordens, agora dou ordens. Quando penso em quantas pessoas estão sob minha responsabilidade, eu penso: não posso errar!” (E8) 
Com base nesses relatos, a necessidade de realização, descrita por McClelland (1961) se destaca como fator motivacional para a atividade empreendedora. Torna-se nítido o senso de propósito (Rosso, Dekas e Wrzesniewski, 2010), que trata tanto da intencionalidade e valoração quantitativa do esforço empreendedor (Grant, 2008; Pratt e Ashforth, 2003 apud Rosso, Dekas e Wrzesniewski, 2010), quanto da convergência dele com o sistema de valores do empresário no processo de significação do trabalho.

\section{Trocando o reconhecimento dos pares pela expansão na autoestima}

Mais uma vez, observou-se uma mudança referente à terceira dimensão do sentido do trabalho (MOW, 1987), no que tange aos resultados e objetivos valorizados. Este ponto ratifica a transferência da origem do sentido do trabalho de "outros" para o "self", conforme a terminologia de Rosso, Dekas e Wrzesniewski (2010). Alguns entrevistados relataram que se sentiam reconhecidos em seus empregos anteriores, o que indica que a opção por empreender não foi decorrente de frustrações no ambiente de trabalho anterior, nem tampouco de sentimentos de desvalorização por parte das chefias. Por este motivo, acredita-se que, ao empreenderem esta significativa mudança profissional, os entrevistados estavam abrindo mão do reconhecimento dos pares e chefias, em busca de uma atuação capaz de ampliar-lhes ainda mais a autoestima, por estar associada a um senso de realização e superação. As falas do Entrevistado 2 ilustram essa troca, que pode ser entendida como a mudança do lócus de reconhecimento como algo externo ao indivíduo:

"Durante o estágio na X, en fiquei sabendo que foi feita uma avaliação de desempenho de toda equipe dos estagiários e meu nome foi citado como destaque na equipe. Isso pra mim foi muito bom." (E2)

Passando a ser, eminentemente interno:

"(...) eu senti a necessidade de testar
outras habilidades. Era muito cedo
pra definir o que eu realmente queria,
naquela época... Eu sou apaixonado por
branding. Queria me testar nisso... E a
minha empresa me deu essa chance, de me
testar em todas as áreas de comunicação."
(E2)

“(...) en senti a necessidade de testar outras habilidades. Era muito cedo naquela época... Eu sou apaixonado por branding. Queria me testar nisso... E a minha empresa me deu essa chance, de me testar em todas as áreas de comunicação."
De um processo de significação que tangenciava questões de pertencimento ao grupo e de significação cultural e interpessoal, o "ex-empregado" passa a dar sentido ao seu trabalho através do alinhamento de suas ações com suas percepções sobre si mesmo, suas capacidades, competências e impacto do resultado de suas ações, num ciclo de auto-valorização e de senso de propósito. Tratam-se dos mecanismos de autenticidade, autoeficácia, autoestima e propósito, descritos por Rosso, Dekas e Wrzesniewski (2010). O senso de realização, de achievement, decorrente da criação de uma empresa e do alcance continuado de objetivos, incluindo os financeiros, traz aos entrevistados a certeza de que são capazes, de que têm valor e de que são bem-sucedidos:

"É muito grande. A minha empresa define muito quem eи sou, é meu legado. Meus filhos têm algo que pertence a eles. Tomei todo cuidado preparando-os para ir adiante com a empresa. Através do men trabalho, pude mostrar meus valores e minha integridade e isto faz parte da minha empresa: compartilho meus valores com ela. Afinal, ela leva o men nome." (E13)

"O trabalho representa a minha fonte de renda. Mas não é só isso também. $O$ trabalho para mim significa um termômetro da pessoa que eu sou: se minha empresa tem sucesso, eu tenho sucesso.” (E7)

"Antes en trabalhava para ganhar o meu salário e pronto. Agora é diferente: meu trabalho é muito importante na minha vida. Cresci em uma comunidade carente, então é muito bom poder mostrar pra todo mundo que eu sou capaz: Quando vejo a minha logo, sinto orgulho de mim. Nunca imaginei que um dia eu conseguiria chegar aonde cheguei, porque eu nunca fui muito de estudar". (E6)

Os resultados financeiros provenientes dos empreendimentos reforçam a sensação de conquista, de potência, são tanto o símbolo de que conseguiram "chegar lá", quanto o principal objetivo do negócio, em alguns casos: 
"Tenho orgulho do meu trabalho, do que eu consegui construir. Além de ser minha fonte de renda, meu trabalho determina minha conta bancária. Quero ganhar muito dinheiro, que a minha empresa esteja estabilizada no mercado... Trabalho como louca, me dedico muito.” (E9)

\section{Considerações finais}

A partir da análise dos relatos dos participantes foi possível perceber algumas mudanças na experiência subjetiva do trabalho em função da transição do status de empregado para o de empreendedor. Para analisar essa transição, quatro vetores principais de mudança foram identificados e discutidos.

O primeiro vetor envolve a transição do status de empregado, uma situação profissional com exigências de dedicação relativamente moderadas, dá lugar à carga de trabalho mais intensa como empreendedor. Porém, esse alto envolvimento e volume de trabalho vêm acompanhados por recompensas financeiras bem superiores aquelas recebidas na condição de empregado, o que, aos olhos desses indivíduos, dá um sentido mais pleno aos esforços empreendidos. O segundo vetor considera a mudança da condição de empregado, vista como promotora de segurança, para o trabalho visto como fonte de autodeterminação e de maior qualidade de vida, como empreendedor. Outro vetor de mudança diz respeito ao aumento no senso de responsabilidade por resultados, relativamente menor na condição de empregado, mas ampliado na vivência como empresário, devido à necessidade de uma atitude mais responsiva e proativa associada ao trabalho nesta condição. Ser empreendedor também parece promover um aumento no senso de propósito, decorrente da condição de proprietário e pelo prazer de fazer uma atividade escolbida como empreendedor. Por fim, observouse também a substituição do reconhecimento pelas contribuições no trabalho, originalmente pautado nos pares e superiores, pela expansão na autoestima através da percepção de sucesso e eficácia pessoal baseada nos resultados do próprio empreendimento.

Postula-se que o registro de tais mudanças seja a principal contribuição teórica do presente estudo ao debate acerca da compreensão do fenômeno sentido do trabalho. A literatura que versa sobre o tema, tanto nacional (Tolfo et al. 2005; Tolfo e Piccinini, 2007; Morin, Toneli e Pliopas, 2007; Cavalheiro, 2010; Tolfo et al. 2011), quanto internacional
(MOW, 1987; Baumeister, 1991; Brief e Nord, 1990; Wrzesniewski, 2003; Rosso, Dekas e Wrzesniewski, 2010), tende a analisar este conceito com foco na ocupação presente dos sujeitos pesquisados, dando pouca ênfase ao caráter dinâmico dessa construção e, consequentemente, às mudanças na percepção dos aspectos subjetivos referentes à atividade profissional. Ao estabelecer dois marcos na trajetória profissional dos sujeitos pesquisados - a condição de empregado e a de empresário - a pesquisa oferece uma abordagem pouco usual na investigação científica acerca do sentido do trabalho e chama atenção para as alterações deste sentido, para um mesmo indivíduo, em decorrência de mudanças em sua vida laboral. De forma conclusiva, pode-se destacar que mudanças de papéis e transições ao longo da vida profissional, desde o ingresso até a saída da esfera produtiva, costumam provocar vivências emocionalmente intensas e transformadoras para as pessoas (Ashforth, 2001). Ao detalhar preliminarmente os processos envolvidos nesse tipo de transição, os resultados da pesquisa evidenciam mudanças significativas no sentido do trabalho com base no self e nos outros em função da transição do papel de empregado para o empresário. Tal mudança se dá, sobretudo, com base em processos associados à ampliação da autoeficácia, autoestima e propósito a partir das vivências do trabalho como empreendedor. Apesar dos riscos e responsabilidades maiores e de jornadas de trabalho também ampliadas, a vivência subjetiva dos esforços empreendidos no trabalho como empresário é legitimada pela experiência subjetiva de um trabalho escolhido, considerado relevante, onde esses sujeitos experimentam maior autodeterminação, senso de propósito e competência, além de receberem ganhos financeiros maiores. Trabalha-se muito, os riscos, as horas, a labuta, são maiores do que na condição de empregado, porém, a experiência intrínseca, subjetiva do trabalho como empreendedor é substantivamente distinta. Nela, a labuta tem seu sentido profundamente modificado, sendo renovado e enriquecido, o que viabiliza a construção subjetiva de sujeito realizador e empoderado pelo próprio trabalho e pelos ganhos materiais dele provenientes. A transição do papel de empregado para o de empreendedor deixa claro, assim, o papel do sentido do trabalho como elementochave na construção do eu e no reforço da identidade profissional. 


\section{Referências Bỉbliográficas}

Ashforth, B.E. Role Transitions in Organizational Life: An Identity-Based Perspective. Mahwah, NJ: Lawrence Erlbaum, 2001.

Ashforth, B. E., \& Mael, F. Social identity theory and the organization. Academy of Management Review, 14(1), 20, 1989.

Baron. OB and Entrepreneurship: The reciprocal benefits of closer conceptual links. Research in Organizational Behavior, Volume 24, pages 225269, 2002.

Baumeister, R. F. Work, work, work, work. In Meanings of Life (pp. 116-144). New York: The Guilford Press, 1991.

Brief, A. P., \& Nord, W. R. Meanings of occupational work. Lexington: Lexington Books, 1990.

Busenitz, L., West III, G. Shepherd, D., Nelson, T., Chandler, G., Zacharakis, A. Entrepreneurship Research in Emergence: Past Trends and Future Directions. Journal of Management, 29(3) 285308, 2003.

Cavalheiro, G. Sentidos atribuídos ao trabalho por profissionais afastados do ambiente laboral em decorrência de depressão. Dissertação (Apresentada à Universidade Federal de Santa Catarina, Florianópolis, SC), 2010.

Dubois, A; Gadde, L. Systematic combining: an abductive approach to case research. Journal of Business Research, 55, 553-560, 2002.

EAESP. $7^{a}$ Pesquisa LIDE-FGV - Perfil do LIDE Futuro. 2014.Disponível em: http:/ / www.lidefuturo. com.br/uploads/informativos $/ 7 \% 20$ pesquisa $\% 20$ FGV\%20no\%20LIKE\%20THE\%20FUTURE.pdf Acessado em: 25/06/2014

Favoreto, R., Binder, M., Campos, A. Um ensaio sobre o campo do empreendedorismo: Considerações sobre uma possível sistematização teórica. FACESI em revista. Ano 4 - Volume 4, N.1, 2012.

Fillion. Empreendedorismo: Empreendedores e proprietários-gerentes de pequenos negócios.

Revista de Administração. São Paulo. v.34, n.2, p.528, 1999.
Grant, A. M. The significance of task significance: Job performance effects, relational mechanisms, and boundary conditions. Journal of Applied Psychology, 93(1), 108-124, 2008.

Global Entrepreneurship Monitor. Global Entrepreneurship Monitor 2013 Global Report. 2014. Disponível em: http:/ / www.gemconsortium. org/docs/download/3106 Acessado em: $24 / 06 / 2014$

Hill, P. C., \& Pargament, K. I. Advances in the conceptualization and measurement of religion and spirituality. American Psychologist, 58(1), 64-74, 2003.

Kubo, S., Gouvêa, M. Análise de fatores associados ao significado do trabalho. Revista de Administração. São Paulo, v.47, n.4, p.540-554, out./nov./dez, 2011.

McClelland, D. C. The achieving society. Princeton (NJ): Van Nostrand, 1961.

Morin, E., Tonelli, M. J. Pliopas, A. Trabalho e seus sentidos. Psicologia \& Sociedade. 19, Edição Especial 1: 47-56, 2007.

Meaning of Work International Research Team. The meaning of working. London: Academic Press, 1987.

Pérezgonzález, J., Vilela, L. La centralidad del trabajo. Dublin: Lulu, 2005.

Rosso, B., Deka, K., Wrzesniewski. A. On the meaning of work: A theoretical integration and review. Research in Organizational Behavior. 30. 91-127, 2010.

Schumpeter, J. A. Teoria do desenvolvimento econômico: uma investigação sobre lucros, capital, crédito, juro e o ciclo econômico. São Paulo: Abril Cultural, 1982.

Sebrae. Global Entrepreneurship Monitor Empreendedorismo no Brasil - Relatório Executivo 2014. 2015. Disponível em http:// www.Sebrae.com.br/Sebrae/ Portal\%20Sebrae/ Estudos $\% 20 \mathrm{e} \% 20$ Pesquisas/gem $\% 202014$ relat $\% \mathrm{C} 3 \%$ B3rio $\% 20$ executivo.pdf Acessado em: 24/06/2015

Stinchcombe, A. L. The conditions of fruitfulness of theorizing about mechanisms in social science. Philosophy of the Social Sciences. 21(3), 367-388, 1991. 
Super, D. E., \&Sverko, B. Life roles, values, and careers. San Francisco: Jossey-Bass, 1995.

Tolfo, S., Piccinini, V. Sentidos e significados do trabalho: Explorando conceitos, variáveis e estudos empíricos. Psicologia \& Sociedade, 19, Edição Especial 1: 38-46, 2007.

Tolfo S.; Grandi, C.; Althof, D.; Picinin, D.;

Noermberg, T. O processo de reestruturação produtiva de uma empresa de telecomunicações: o caso dos trabalhadores remanescentes, demitidos e que aderiram ao PDI. EnANPAD 2005, Porto alegre, v. 29, p. 473, 2005.

Tolfo, S. da R., Coutinho, M. C., Baasch, D. \& Cugnier,J. S. Sentidos y significados deltrabajo: unanálisiscon base en diferentes perspectivas teórico-epistemológicas em Psicología.

UniversitasPsychologica, 10(1), 175-188, 2011.

Vale, G. Tréplica - Afinal de Contas, Que Bicho

é Esse? Tréplica sobre o Empreendedor e o

Empreendedorismo. RAC, Rio de Janeiro, v. 18, n. 6, pp. 900-908, 2014.

Wiseman, R. W., \& Skilton, P. F. Divisions and differences: Exploring publication preferences and productivity across management subfields. Journal of Management Inquiry, 8: 299-320, 1999.

Wrzesniewski, A. Finding positive meaning in work. In K. S. Cameron, J. E. Dutton, \& R. E. Quinn (Eds.), Positive organizational scholarship. San Francisco: Berrett-Koehler Publishers, Inc., 2003. 